Talía. Revista de estudios teatrales

ISSN-e: 2659-806X

http://dx.doi.org/10.5209/TRET.63214

\title{
El teatro de Lope y la censura (siglo XVII) ${ }^{1}$
}

\author{
Marco Presotto*
}

Recibido: 8 de julio de 2018 / Aceptado: 29 de octubre de 2018

Resumen. El artículo propone un panorama crítico sobre la censura teatral de la obra de Lope de Vega en el siglo XVII. A partir de los datos disponibles y de los estudios recientes, el autor llega a definir las principales tipologías de intervención que pueden documentarse con certeza, mientras que da cuenta de casos significativos de revisión de piezas donde solamente pueden hacerse hipótesis sobre los motivos de los cambios realizados, entre la más que probable presión externa y el constante afán de reescritura por parte del dramaturgo.

Palabras clave: Censura, Teatro, Lope de Vega, Manuscritos

\section{The plays of Lope and the censorship (XVII ${ }^{\text {th }}$ Century)}

\begin{abstract}
The article proposes a critical panorama on the theatrical censorship of the work of Lope de Vega in the XVII century. From the available data and recent studies, the author defines the main types of intervention that can be documented with certainty, while accounting for significant cases of review of pieces where only hypotheses can be made about the reasons for changes, between the more than likely external pressure and the constant intention for rewriting by the dramatist.
\end{abstract}

Keywords: Censorship, Theater, Lope de Vega, Manuscripts

Cómo citar: Presotto, M. (2019). "El teatro de Lope y la censura (siglo XVII)", en Talía. Revista de estudios teatrales, $1,9-25$

\section{Autopromoción y mercado}

En los estudios sobre el teatro de Lope de Vega, la relación con la censura teatral ha sido abordada tradicionalmente de manera esporádica a falta de un corpus documental que permitiera obtener resultados de conjunto. Gracias al imponente trabajo sobre la censura del teatro del Siglo de Oro realizado por el grupo de investigación CLE$M I T^{2}$, tenemos ahora suficientes elementos para trazar un panorama de esta faceta

* Universidad de Bolonia.

1 Este trabajo se enmarca en los resultados del proyecto PRIN 2015 - Prot. 201582MPMN, "Il teatro spagnolo (1570-1700) e l'Europa: studio, edizione di testi e nuovi strumenti digitali".

2 Censuras y licencias en manuscritos e impresos teatrales, grupo dirigido por Héctor Urzáiz desde la Universidad de Valladolid, tiene una página donde aloja sus publicaciones y actividades (www.clemit.es) y una base de datos en línea (www.buscador.clemit.es) donde se pueden consultar muchos de los datos manejados en este trabajo; nuestras referencias a CLEMIT remiten a esta base de datos. 
importante en el sistema comercial de la comedia nueva que el mismo Lope contribuyó a fijar de manera estable. Es posible que la censura haya conseguido silenciar textos en tal medida que no se conserve hoy ningún rastro de ello, y por lo tanto cualquier conclusión debería considerarse provisional. Al mismo tiempo, resultará conveniente tener presente el papel que mantuvo o intentó alcanzar el escritor en las complejas dinámicas sociales, políticas y culturales del Madrid de su época. En este contexto, Lope realizó su constante actividad de autopromoción y trazó como pocos la ruta hacia un estatus semiprofesional del escritor, que representa una de las mayores novedades de su perfil biográfico.

Como es sabido, el autor del Arte nuevo de hacer comedias llegó a teorizar irónicamente un modelo productivo que justificara ante la élite cultural el protagonismo extraordinario que conoció su obra en los corrales por varios decenios. El objetivo prioritario de la escritura teatral es su venta y el beneficio económico, de ahí el difícil camino que llevará al reconocimiento de su valor literario; es evidente que la atención hacia los posibles motivos de veto por parte de la censura debió de ser uno de los ingredientes básicos del proceso creativo de Lope. La falta de aprobación de una obra presentada ante las autoridades o la suspensión de su representación significaban directamente la interrupción de una actividad comercial que iba a perjudicar una cantidad muy amplia y variada de categorías profesionales.

También es importante considerar las diferentes etapas, tanto del comercio teatral como de la actividad artística y cultural del mismo Lope, que llegó a ser nombrado familiar del Santo Oficio, y más tarde Procurador fiscal de la cámara apostólica en el arzobispado de Toledo después de haber tomado las órdenes en 1614. De hecho, a partir de estos años, el mismo autor realiza con frecuencia censuras de libros de los géneros más variados, entre ellos teatro, pero siempre en el contexto oficial de aprobación de los textos para su publicación, por lo tanto dentro de unas dinámicas y unas funciones distintas con respecto al permiso para la puesta en escena ${ }^{3}$. El protagonismo de Lope en el ambiente cultural de la época se confirma por la buena relación, que llega hasta la directa amistad, con los principales censores madrileños. Tomás Gracián Dantisco, celebrado por Cervantes, aprueba un gran número de comedias de Lope hasta 1621, año de su muerte, mientras que en la época de Felipe IV (1621-1634), Pedro de Vargas Machuca, poeta además de censor y amigo del escritor, es el principal autor de las licencias de representación de sus obras ${ }^{4}$.

En este contexto de relativa sintonía entre el dramaturgo y los mecanismos de control de sus obras, debe valorarse uno de los casos más interesantes de censura que conocemos, aunque parcialmente, y nos ha llegado gracias a la firme protesta que desató.

3 A pesar de una metodología en parte opinable, sigue manteniendo un cierto interés el libro de Zamora Lucas (1941), que da cuenta de las 55 aprobaciones de Lope a textos impresos, principalmente realizadas a partir de los años veinte. Algunas de ellas son muy amplias y demuestran cómo este paratexto se había convertido, como la dedicatoria, en un instrumento funcional al elogio, el comentario erudito, la promoción y la polémica literaria. De allí la especial importancia que reviste el nombre del autor de tales permisos de publicación.

4 Lope celebra a Vargas Machuca en su Laurel de Apolo (Silva VIII, vv. 509-524, p. 256). No conocemos hasta qué punto el autor pudo elegir los censores de sus comedias, que en algunas licencias declaran explícitamente una profunda admiración: "Pocas veces tienen las comedias de Lope de Vega Carpio qué advertir, porque lo es él tanto en sus escritos que no deja en qué reparar, y en esta del Amor, pleito y desafio, ha mostrado su ingenio y atención. Madrid, 14 de enero de 1622. Puédese representar". Esto no elimina la posibilidad de que el censor exija pequeñas intervenciones en lugares concretos. 
En 1608, una comedia de Lope sobre la conversión de San Agustín fue retirada de las tablas, posiblemente a causa de una denuncia al Santo Oficio; según el documento conservado, la reacción del poeta fue a la altura de los perjuicios que esta orden había causado a los profesionales del teatro. Lope se queja contra las autoridades por lo que representa, bajo su punto de vista, una injusticia. Consciente de relacionarse con una institución administrativa que considera cercana a él, el dramaturgo exige indicaciones que permitan devolver la obra al mercado teatral de la manera más rápida posible. Vale la pena volver aquí a reproducir por entero el texto:

Lope de Vega Carpio familiar del Santo Oficio de la Inquisición digo, que de haber Vuestra Alteza [i.e.: el Consejo Supremo de la Inquisición] mandado recoger una comedia que yo escribí de la conversión de San Agustín, por haber tenido algunos argumentos indecentes para representarse en parte pública, me ha resultado grande nota en mi honor y reputación, hablando en mí diversas personas con diversos juicios, por lo cual suplico humildemente a Vuestra Alteza que, con su acostumbrada benignidad, se sirva de que tildando y borrando todo lo que pareciere convenir que sea quitado y borrado, se me vuelva la comedia para que yo la vuelva a escribir, y poner en el modo que es bien que esté para poderse representar, que luego la volveré a Vuestra Alteza para que en ella se haga la censura y calificación que antes, que desta suerte se entenderá claramente la verdad y yo quedaré restituido en mi honor y buena opinión, y Vuestra Alteza favorecerá un criado suyo tan deseoso y cuidadoso de servir ese Santo Tribunal a cuyos pies me postro humildemente, pidiendo esta merced por algunos, aunque pequeños servicios, y por los que pienso hacer lo que tuviere de vida. Lope de Vega Carpio ${ }^{5}$

El documento contiene varios indicios de interés. Testimonia una práctica, aquí solicitada y no sabemos cuánto difundida, de reescritura del autor después de haber recibido indicaciones específicas sobre los lugares que no podían representarse. Los "argumentos" citados por Lope son supuestamente secuencias dramáticas enteras, que necesitaban la revisión atenta por parte de un poeta para poderse modificar de manera satisfactoria de cara a la puesta en escena. Unas intervenciones poco cuidadas, solamente dirigidas a eliminar el texto censurado, podrían llevar a incongruencias en la acción y al fracaso de la representación. También resulta evidente en la solicitud la gravedad del daño de imagen que una acción como esta podía significar para el dramaturgo, tanto en relación con el ambiente mundano y literario como con las compañías teatrales. No sabemos si la obra sobre San Agustín a la que se refiere es El divino africano, publicada en la Parte XVIII de sus comedias (1623) y fechada en torno a 1610; por lo visto, no es fácil encontrar en el texto que nos ha llegado elementos pasibles de una censura total como la que sufrió la pieza citada en el documento. Es de esperar que se encuentren en el futuro más datos para reconstruir este caso interesante que afectó directamente a Lope, no sabemos con qué resolución final (un estado de la cuestión se encuentra ahora en la ficha correspondiente en CLEMIT) ${ }^{6}$.

5 Apud Castro; véase también Zamora Lucas [1941: 33-34] y las aportaciones de Granja 2006 y Florit 2010, referencias recogidas y comentadas en CLEMIT. Véase también Márquez [1980: 167]. El documento se conserva en el Archivo Histórico Nacional de España, Sección de Inquisición, con signatura MPD.246 (Legajo 1952, según Zamora Lucas).

6 Otro episodio de gran interés, que conocemos de manera muy parcial, atañe la última época de la actividad teatral de Lope. Según la relación de un embajador del gran duque de Florencia en España, en 1633 se 1 legó 


\section{Documentación y etapas}

La reconstrucción del sistema comercial del teatro de corral tiene entre sus bases documentales principales el "original", manuscrito autógrafo o autorizado de la pie$\mathrm{za}$, que representa el objeto de transacción entre el poeta y el autor de comedias, y permite la activación de la producción espectacular, que tiene como trámite obligado la presentación del mismo manuscrito a las autoridades para la aprobación. Gracias a la imponente cantidad de obras conservadas de Lope, al prestigio de su nombre en el mercado y a la voluntad de su mecenas, el Duque de Sessa, conservamos un buen número de estos manuscritos ${ }^{7}$. Tales documentos constituyen la fuente directa, y casi exclusiva, para reconstruir el itinerario administrativo y de control al que se sometían estas obras literarias antes de pasar a la puesta en escena pública. Gracias al amplio espectro temporal que cubren las comedias manuscritas conservadas, es posible también obtener indicios sobre el influjo que debieron de ejercer en la actividad censoria eventos importantes o el aumento de la presión de los moralistas en los momentos de intensificación del debate sobre la licitud del teatro. Sin duda el cierre de los teatros tras la muerte de Felipe II debió de marcar sensiblemente el nivel de atención de los censores en el momento de la reapertura en $1599^{8}$, ocasión propicia para aumentar la presión de los opositores de este fenómeno considerado promiscuo y potencialmente subversivo tal como se había desarrollado en la sociedad urbana de la época. Se conservan muy pocos originales de Lope fechados en estos años, a pesar de la presencia ya asentada de su nombre en el mercado teatral; afortunadamente han llegado unas copias del siglo XVIII ${ }^{9}$ de algunos autógrafos ahora perdidos, en los que el copista trasladó diligentemente las licencias de representación que pudo leer, ofreciendo hoy una ayuda importante para reconstruir esta fase peculiar de las relaciones entre poder y comercio teatral.

El blasón de los Chaves de Villalba es una comedia escrita en 1599 que remite en las licencias a una práctica de control seguramente prevista pero poco común, es decir la representación privada ante las autoridades para su aprobación. El tema era delicado, tratándose de un drama histórico sobre las guerras entre Francia y España en Italia en la época de los Reyes Católicos y Luis XII de Francia, pero se debía poner en escena en un momento de buenas relaciones entre los dos países, que el Duque de Lerma estaba interesado en mantener. De forma parcial y poco atenta, los censores decidieron sustituir las referencias a Francia con Albania, dejando varias imperfecciones métricas y dificultando la comprensión de algunos pasajes. La

a retirar de las tablas una pieza, ahora perdida, sobre la muerte del rey de Suecia Gustavo Adolfo II durante la Guerra de los Treinta Años acaecida el 6 de noviembre de 1632 en la batalla de Lützen. El dramaturgo debió de escribir la comedia poco después de haber llegado la noticia a España, dado que la obra se estrenó en Madrid el 26 de enero de 1633. Según las relaciones, la pieza fue censurada por orden del mismo Felipe IV que había asistido secretamente, junto con el conde-duque de Olivares, a una representación de la obra en el corral. Este episodio debió de afectar mucho al anciano Lope y a sus pretensiones frustradas en la corte, aunque no se conservan datos sobre su reacción, y debe considerarse execpcional. Tal como indica Teresa Ferrer, "Lope se había atrevido a dar consejos de gobierno por boca de sus personajes al mismo Rey" [Ferrer 2012: 57].

7 Al catálogo de Presotto (Le commedie) hay que añadir ahora el descubrimiento de Crivellari, publicado en 2015, de un nuevo autógrafo teatral de Lope: la comedia Barlaán y Josafat.

8 Sigue siendo fundamental la magna recopilación de Cotarelo y Mori 1904, de la que proceden principalmente las importantes síntesis que se han realizado sobre el debate ético y estético, como las de García Berrio 1978 y Vitse 1988, entre otros.

9 Se trata de los llamados manuscritos Gálvez, del nombre de su copista, estudiados por Silvia Iriso 1997. Aprovecho aquí en parte los contenidos de mi artículo "Libertad y proceso de escritura en Lope de Vega" (2018). 
licencia se concentra en la necesidad de eliminar algunos breves fragmentos y topónimos concretos; el juicio no afecta mínimamente al autor, pero pudo constituir un antecedente para el dramaturgo sobre la oportunidad de tratar determinados temas en el teatro de corral en esos años (véase CLEMIT). De hecho, la guerra de Italia de Luis XII vuelve a aparecer en El genovés liberal, bastante cercana cronológicamente (1599-1603) aunque publicada en la Parte IV (1614) de las comedias de Lope, pero el argumento es muy distinto, y el conflicto político no afecta directamente a España siendo, además, muy diluido en una pieza donde adquiere gran importancia la intriga amorosa.

El amigo por fuerza es una comedia palatina escrita en el mismo período (1599, y publicada en la misma Parte IV) en la que Tomás Gracián Dantisco exigió la sustitución de los topónimos de Bohemia y Hungría con Tracia y Frisia. Como han aclarado en su edición Pontón y Laplana (930), la boda de Felipe III con Margarita de Austria, y la renovada unión del imperio que esto suponía, no hacía conveniente que la acción se realizase en lugares tan concretos del dominio de los Habsburgo, perdiendo además el exotismo que caracterizaba este subgénero dramático ${ }^{10}$. Supuestamente no se pidió a Lope corregir el texto, sino que se hizo de manera parcial y poco atenta, lo cual produjo defectos graves de rima y de metro y algunos problemas de coherencia de la acción. Este cambio de topónimos no se encuentra en el texto impreso en la Parte $I V$, que remite a un tercer nivel de censura, el de la licencia de publicación.

En el momento en que el teatro se convierte en un género editorial de éxito y empiezan a publicarse las partes de comedias, se someten al proceso de control de los libros impresos. Establecer hasta qué punto esta actividad pudo modificar los textos es tarea dura, dado que no se conserva documentación explícita. Las muchas variantes que normalmente se encuentran entre la tradición manuscrita (por lo común preventiva y ligada al mundo de las compañías teatrales) y la tradición impresa (generalmente posterior a la representación), a veces contienen indicios clarísimos de una intervención censoria, pero no es posible establecer si ésta se realizó en el momento de la puesta en escena o, en cambio, en el contexto del proceso de impren$\mathrm{ta}^{11}$. También es verdad que en varias ocasiones el texto impreso restituye fragmentos que habían sido tachados por los censores en el original, lo cual demuestra la escasa relevancia de estas imposiciones al pasar de los años o del canal de difusión ${ }^{12}$.

Toda la llamada propuesta teatral del primer Lope se caracteriza, por otra parte, por ser una dramaturgia en evolución, que está buscando modelos formales e ideológicos eficaces para la realización de un sistema estable de producción y distribución comercial. Son muchos los ejemplos de este teatro más libre, y no es fácil aclarar hasta qué punto algunas modificaciones del texto en los años dependan de una censura externa o simplemente de una labor de autocontrol, tanto del poeta como del "autor de comedias".

10 La atención a las relaciones políticas extranjeras por parte de los censores se encuentra, curiosamente, en la licencia a El marqués de Mantua, cuya ambientación histórico-legendaria asegura "ser antigua y honrosa historia y que en nuestro tiempo no puede ofender a ninguna nación" (véase CLEMIT).

11 Entre diferentes ediciones de una misma comedia pudieron producirse fenómenos de censura, como quizá ocurrió con La comedia de Bamba, compuesta en torno a 1597-1598, cuya segunda edición de Valladolid elimina la descripción elogiosa de los árabes en varios lugares (567).

12 Es el caso, entre otros, de Los embustes de Celauro, aprobada para la imprenta por el mismo Gracián Dantisco que había impuesto las censuras unos años antes, véase Presotto "Reajustes..."; ocurre lo mismo con El amigo por fuerza. 
El perseguido es un drama palatino anterior a 1596, que presenta a menudo una comicidad grosera y alusiones sexuales explícitas poco frecuentes o del todo ausentes en el Lope maduro. Entre un manuscrito temprano y el impreso ${ }^{13}$ se encuentran muchas variantes, que en buena parte reducen las alusiones a la supuesta homosexualidad del protagonista y la vulgaridad de algunas secuencias. Se trata sin duda de una forma de censura, aunque no puede saberse en qué momento de la transmisión textual tuvo que producirse.

Otro caso análogo es el de El nacimiento de Ursón y Valentín, una pieza escrita en los años noventa del siglo XVI y publicada en la Parte I (1604) pero también conservada en un manuscrito de la colección Gondomar estudiada recientemente por Josefa Badía (2014). Entre la gran cantidad de variantes que separan el manuscrito del impreso, así como las indicaciones de fragmentos tachados pero recuperados por el copista, los editores Campana y Mayol (993), indican una entera secuencia que trata de manera burlesca de la guerra con un lenguaje especialmente vulgar y de tono escatológico, luego eliminada en la Parte I. Lo cierto es que la tendencia a la limitación de determinados registros y alusiones corre pareja a la búsqueda de un modelo cómico y al afianzamiento del papel del "poeta" en el sistema comercial de la comedia nueva.

La atención al decoro en las secuencias cómicas es patente en varias licencias, entre ellas sin duda La bella malmaridada, una comedia urbana que se escribe poco antes del cierre de los teatros (1596). El protagonismo del ambiente bajo urbano lleva a la constante referencia al amor carnal, la prostitución y un erotismo muy explícito. Se conserva una copia antigua del manuscrito autógrafo, que recoge las intervenciones del censor Gracián Dantisco donde impone la eliminación de la descripción burlesca de las mujeres de vida (vv. 2806-2829), que remite a un lejano eco ovidiano.

En los mismos años, sufre una censura parecida La francesilla, otra pieza anterior al cierre de los teatro (1596), muy descarada con explícitas alusiones sexuales. La tradición textual presenta un manuscrito del siglo XVIII de la colección Gálvez y el impreso de la Parte XIII (1620). El apógrafo contiene una serie de estrofas en apéndice porque se encontraban recuadradas en el original para su eliminación; algunos de estos fragmentos se caracterizan por un fuerte erotismo, y también el impreso presenta muchas omisiones que moderan en su conjunto esta peculiaridad del texto. Son dos tendencias complementarias, que remiten a distintos ámbitos de la revisión de la obra y para finalidades distintas (la representación y la lectura), pero ambas nos conducen a un mismo proceso de control interno de la pieza, no tanto a un sistema oficial de censura, sino a una forma creciente de autocontrol dentro del mundo de la producción teatral.

Otro aspecto que recibe una especial atención a finales del siglo XVI es la referencia a la divinización de la dama, tópico de la tradición de amor cortés revitalizado por el motivo de la donna angelicata de la poesía renacentista italiana y que hace parte del vocabulario de toda la poesía amorosa de la época. Por lo visto, en varias comedias de estos años el censor exige la eliminación de la referencia a la dama

13 La pieza hace parte del volumen que inaugura la tradición del teatro impreso, es decir Seis comedias de Lope de Vega y de otros autores, Lisboa, por Pedro Crasbeeck, a costa de Francisco López, 1603 y luego se vuelve a publicar en la Parte I de las comedias de Lope (1604). Como ha documentado Valentina Nider (2011), esta obra se representó en 1616 en Florencia junto con el Entremés de la Palancona y la comedia burlesca Durandarte y Belerma; todo el espectáculo, organizado por la comunidad judía portuguesa, fue denunciado al Santo Oficio. 
como un ángel. Así ocurre por ejemplo en Los embustes de Celauro, fechada a 25 de enero de 1600, en un período muy cercano a la reciente reapertura de los corrales; Gracián Dantisco el 30 de octubre del mismo año censura varios de los nueve lugares donde aparece esta imagen, como la siguiente quintilla:

Norabuena yo merezca,

después que el sol amanezca,

ver un ángel como vos,

donde la imagen de Dios

más al vivo resplandezca. (vv. 387-391)

En la misma licencia, Gracián Dantisco impone una especial atención por parte de los actores hacia la manera "de decir de adorar en las partes donde usan esta frasis, lo cual podrán allá acomodar para que todos entiendan cómo se pueden decir estos encarecimientos" (CLEMIT); también la referencia al abismo infernal por parte del personaje de Celauro resulta tachada por el censor. Una actitud parecida se encuentra en El amigo por fuerza, cuya censura del 3 de noviembre de 1600 impone la eliminación del verbo adorar en dos ocasiones y de la metáfora angelical ${ }^{14}$, aspecto que se da también en las muchas intervenciones que aparecen en el autógrafo de La corona merecida (1603) estudiada por Urzáiz ("Arte nuevo...") y retomadas de forma sistemática en una interesante subdivisión por Rodríguez Gallego en su edición de la obra (799-829). Posiblemente estas censuras, contradictorias con respecto al léxico del lenguaje amoroso renacentista y barroco, remiten a una normativa específica, observada en el período cercano a su publicación pero destinada a caer en el olvido con el paso de los años ${ }^{15}$.

El caso de La corona merecida vuelve a poner de manifiesto la dificultad de distinguir con exactitud los diferentes momentos de revisión de una pieza y el nivel de influencia, directa o indirecta, de la censura oficial. Por un lado está, como vemos, el dictamen de las autoridades, por otro la atención de los poetas que no tienen interés en incurrir en estos impedimentos a la realización del negocio. Pero también están las necesidades de la puesta en escena que pueden variar en determinadas condiciones de producción, lo cual supone una lectura del autor de comedias o de un encargado suyo y la modificación -por lo común, la eliminación- de secuencias o breves fragmentos que no se consideran oportunos para aquella ocasión. Dentro de esta remodelación, puede caber una forma de autocensura, expresamente solicitada o tan solo inducida por el contexto del momento. Es por esto que varios autógrafos de Lope resultan muy estragados, con indicaciones "sí" y "no" en los márgenes de las páginas que indican una reiterada reflexión sobre la oportunidad de aprovechar o

14 El manuscrito copia del siglo XVIII de Viuda, casada y doncella, comedia de 1597, recoge la licencia de representación de Gracián Dantisco del 15 de octubre de 1600 que incluye la censura de un total de cuatro versos (dos en el primer acto y dos en el tercero "que se han de decir como están allí enmendados"); no parece posible reconocer estos versos dado que no se encuentra en el texto copiado ninguna referencia a ello, pero es de suponer que la tipología de intervención fuera parecida a las indicadas, así como ocurre con La imperial de Otón, pieza de 1600 con licencias que indican que unos versos tenían que borrarse por indecentes (véase CLEMIT).

15 Sin embargo, en el autógrafo de la comedia muy posterior Amor con vista (1626), que no parece presentar censurar explícitas, aparece una página entera cuyo texto está tachado con líneas circulares, muy atípicas con respecto a la costumbre de Lope, donde se elimina una secuencia en la que el galán enamorado compara la dama a un ángel [Presotto 2000: 77]. 
desechar una parte del texto según las necesidades que se produjeran. En esta tipología textual, reconocer a ciencia cierta una censura oficial es tarea dura ${ }^{16}$.

Es indudable que en los años cercanos a 1600 la atención debió de ser mayor, y tuvo que influenciar en algunos casos la misma manera de elaborar el objeto artístico a partir de los modelos utilizados, como señala Teresa Barjau en su edición de la comedia La pobreza de Reinaldos. Esta pieza pertenece al grupo de comedias escritas para la compañía de Pinedo entre 1599 y 1606, estudiadas por Wilder y Profeti. La comedia se basa sobre varias fuentes caballerescas; Lope prefiere no aprovechar las aventuras amatorias para obtener un perfil del héroe ajustado a la ortodoxia tridentina, ya que el protagonista "es presentado como ejemplar padre y esposo que sigue al pie de la letra la moral familiar de la Epístola a los Efesios de San Pablo (V, 21-23 y VI, 1-9)" [Barjau 2008: 334].

Es evidente que algunos subgéneros teatrales o temas tratados quedan sometidos a un nivel más elevado de atención. El niño inocente de La Guardia es una comedia sobre la condena a muerte del converso Benito García por asesino ritual de un niño cristiano en 1490; la pieza se escribió probablemente en torno a 1603 y se publicó en la Parte VIII (1617); se conserva un manuscrito que omite muchos versos, probablemente por necesidades de la representación, pero las intervenciones afectan a varios lugares que tocan temas de la fe cristiana o de condena de los judíos: implican figuras reales y el mismo Santo Oficio, como ocurre al principio de la obra en el diálogo entre Isabel la Católica y el Marqués de Santillana sobre la oportunidad de combatir la herejía (vv. 4-48) ${ }^{17}$. La posibilidad de que estemos ante una acción de tipo censorio es muy elevada, pero a falta de datos concretos es imposible establecer de parte de quién se realizó y con qué objetivo.

A partir de los años de madurez de Lope, una vez afirmado el modelo teatral y establecido el mercado de la producción espectacular, la actividad que podemos documentar de la censura en sus textos se hace más esporádica, aunque a veces sorprendente; también el lenguaje dramático ha cambiado, así como la conciencia del dramaturgo acerca del funcionamiento del sistema de control y de los aspectos más sensibles. Las licencias a sus comedias tienden a una formulación repetitiva y el censor, las más veces el mismo Pedro de Vargas Machuca amigo de Lope, a menudo aprovecha la ocasión para alabar el autor, como ya se ha apuntado. En las comedias de asunto histórico o hagiográfico, el encargado dedica más líneas de lo usual para dar cuenta de la fidelidad del texto con respecto a la verdad de la historia, aspecto de especial interés por parte de las autoridades y también motivo sensible de promoción de Lope en sus ambiciones de llegar a obtener el cargo de cronista real ${ }^{18}$. El debate sobre la licitud volverá a tomar vigor después de la muerte del escritor, cuando su herencia llegará a representar simbólicamente un patrimonio objeto de polémica y de rechazo por parte de los moralistas. Según apuntaba Casiano Pellicer, en la Consulta para volver a abrir los teatros en 1644 después de la suspensión por la muerte de la Reina doña Isabel, el Consejo de Castilla indicó claramente:

16 Entre los varios casos que podrían citarse, véanse en CLEMIT las fichas relativas a La discordia en los casados, obra de 1611, y también Carlos V en Francia, escrita en 1604.

17 Remito para más detalles a la edición de la comedia por parte de Fernando Baños Vallejo [2009]; véase también la ficha correspondiente en CLEMIT.

18 Véanse en CLEMIT, entre otras, la licencia a El Brasil restituido y especialmente a El Marqués de las Navas, donde el censor llega a defender la verdad poética del texto de Lope frente a la leyenda representada. 
Que las comedias se redujesen a materias de buen ejemplo, formándose de vidas y muertes ejemplares, de hazañas valerosas, de gobiernos políticos, y que todo esto fuese sin mezcla de amores; que para conseguirlo se prohibiesen casi todas las que hasta entonces se habían representado, especialmente los libros de Lope de Vega, que tanto daño habían hecho en las costumbres ${ }^{19}$.

\section{Hacia una tipología de la intervención censoria}

Como se ha podido apreciar, la actividad de censura oficial y modificación de los escritos dramáticos de Lope se concentra en la primera etapa de su producción; quizá a causa de la fuente documental casi exclusiva de la cual disponemos, es decir las licencias de representación ligadas a los manuscritos oficiales de las piezas, las intervenciones de las autoridades son generalmente muy puntuales, no exigen la reescritura de secuencias enteras y se concentran en eliminar palabras, imágenes o referencias que consideran no oportunas en el momento concreto de la evaluación de la obra para la puesta en escena. Esta tipología unívoca de fuente tiene el peligro de ofrecer una imagen parcial del fenómeno, dado que da cuenta solamente del proceso de control de piezas que fueron autorizadas. Tenemos muy pocos indicios de censura total de una obra, entre ellos el de la comedia sobre San Agustín que he señalado al principio; este tipo de evento, de haberse producido, debería haber causado unas cuantas reacciones y escritos sobre ello, dada su gravedad. Es verdad que los subgéneros de las comedias o dramas historiales $^{20}$, y en particular las comedias hagiográficas, exigen una mayor atención del censor, como hemos visto. La atención a la imagen de la historia dinástica de la corona, y las posibles concesiones a la tradición popular que Lope aprovechaba ampliamente, se mantiene también en los demás subgéneros, para evitar el peligro de que el público pudiera asociar una ambientación o una evocación a la actualidad política.

1. Topónimos y antropónimos: una tipología de acción censoria documentada en los años es la de modificar el espacio dramático imponiendo la modificación de los topónimos para evitar posibles alusiones al contexto contemporáneo. Después de los ejemplos ya señalados de El amigo por fuerza (1599), donde Bohemia y Hungría se sustituyen por Tracia y Frisia, y de El blasón de los Chaves de Villalba (1599) en la que Albania reemplaza Francia, unos años después, ocurrió una censura muy similar con el drama palatino La batalla del honor de 1608: Albania ${ }^{21}$ resulta una localización suficientemente exótica y sin posibles referencias con la actualidad también en El cuerdo loco ${ }^{22}$, donde

19 Apud Pellicer 150. Los libros a los que se refiere son las partes de comedias que se habían publicado en vida del autor.

20 Para la subdivisión de la obra dramática de Lope en subgéneros, utilizo el mapa conceptual de Joan Oleza presente en Artelope.

21 La modificación en La batalla del honor no es sistemática y quedan muchas referencia al territorio francés: "Quizás el compromiso matrimonial contraído en 1611 entre el futuro Felipe IV e Isabel de Borbón, hija de Enrique IV de Francia, animara a eliminar del texto una ambientación francesa que pudiera resultar ofensiva, aunque, finalmente, la intención no llegó a materializarse por completo" (Saez Raposo 943). Véase también la edición de la comedia a cargo de Ramón Valdés.

22 Véanse las ediciones de Sánchez Jiménez y Saez [2015: 727] y de Fernández Montesinos [1922: 155-156], quien señala también la presencia del topónimo en La fuerza lastimosa, aunque allí aparece de manera marginal; un excelente resumen de la cuestión puede encontrarse en la ficha relativa a El cuerdo loco en CLEMIT. Albania 
sin embargo el censor exige la sustitución del nombre de Filipo con Lisipo, quizá para evitar la posible asociación con el nombre del Rey. También en El piadoso aragonés (1626) Vargas Machuca exige la eliminación de dos coplas enteras que citan a Juana de Trastámara con el apodo de "Beltraneja" y su supuesta liviandad (puede verse en CLEMIT).

Es interesante notar cómo esta tipología de intervención prescinde de las posibles consecuencias sobre la coherencia formal de la obra, que en cambio puede quedar afectada de manera significativa tanto por los defectos métricos que supone como por la estructura dramática, que supuestamente un encargado de la compañía tenía que arreglar en poco tiempo sin una especial atención a la calidad estética de los reajustes.

2. Registro: a pesar de las muchas suposiciones que pueden hacerse en torno a la causa de la eliminación de amplias secuencias en la tradición textual, en las censuras oficiales conservadas las autoridades parecen limitarse a intervenir sobre el registro lingüístico de algunas breves secuencias cómicas, individuando palabras o sintagmas aislados e imponiendo así intervenciones muy puntuales, que pueden llevar a la eliminación de una estrofa relativamente larga, como en La bella malmaridada ( 24 versos), pero que no implican una revisión importante de la pieza. Al caso de la metáfora angelical ya citado anteriormente, podría añadirse como posible indicio para un estudio, en el autógrafo de la comedia Amor pleito y desafio, una intervención, con rúbrica no de Lope en el margen, que sustituye el verbo "estupró" por el sinónimo "violó", que parecería compatible con una práctica de censura, aunque la sustitución no parece entrar en la tipología de intervención prevista para el revisor (véase en CLEMIT).

3. Actio e indumentaria: especialmente en la época temprana de fijación del modelo teatral de la comedia nueva, y de presencia fluctuante de normativas más o menos respetadas y reiteradas, los censores pudieron imponer una especial atención a la declamación del actor, para mantener el decoro en la expresión de determinadas palabras o imágenes poéticas, como se ha visto con la referencia en Los embustes de Celauro al uso teatral de la palabra “adorar". En la misma comedia, además, Gracián Dantisco impone también unas limitaciones al traje de la dama vestida de hombre: "Adviértese también que cuando la Fulgencia sale en hábito de hombre sea con traje largo como está ordenado, sin que se le vean las piernas", que debe remitir a una orden reciente que citaba expresamente este aspecto ${ }^{23}$.

\section{Autocensura y reescritura}

Además de las intervenciones explicitas del sistema censorio oficial, reviste una notable relevancia la definición de las tipologías documentadas de autocensura en los

\footnotetext{
aparece como espacio dramático en un tiempo histórico indeterminado o maravilloso en el drama palatino de Lope El triunfo de la humildad y soberbia abatida, escrito probablemente entre 1612 y 1614, y en la comedia pastoril de autoría dudosa, El premio riguroso y amistad bien pagada, fechable entre 1595 y 1605 . Para mayores informaciones sobre estas piezas, véase Artelope.

23 Con toda probabilidad, esta indicación tiene en cuenta la orden citada por Luis Cabrera de Córdoba fechada a 4 de febrero de 1600: "que las mujeres que representaren no se pongan hábito de hombre, sino trayendo vaqueros largos" [Apud Presotto 2000: 62].
} 
textos de Lope. Si es cierto que el dramaturgo aprovecha tendencialmente cualquier ocasión para revisar sus textos, mejorar algunas imágenes poéticas, sustituir un epíteto o hasta reescribir estrofas enteras, también es verdad que los lugares que remiten con mucha probabilidad a una acción de autocensura son escasos, y no se conserva documentación completa sobre ellos. Es imposible establecer con certeza en qué fase del proceso de producción teatral se realizaron, si se debieron a una imposición de las autoridades, a la solicitud de la compañía o, simplemente, a una suma de factores más o menos coercitivos que llevaron al autor a retomar su original para modificar de manera significativa secuencias completas o referencias puntuales a lo largo de toda la obra. En este sentido, solamente los manuscritos autógrafos ofrecen indicaciones al respecto, aunque es sabido que la estratificación de intervenciones que a menudo presentan estos documentos dificulta mucho la definición de las diferentes fases de revisión y de sus distintas finalidades.

El caso más interesante es sin duda el de una comedia hagiográfica de 1610, La buena guarda, basada sobre la leyenda de la sacristana, de amplia tradición medieval. Hay varios indicios que llevan a suponer que la pieza fue objeto de especial atención por parte de las autoridades. La licencia de representación tardó casi dos meses desde la orden, y está fechada a 16 de junio por parte de Tomás Garcián Dantisco, que apunta claramente que la obra fue vista y aprobada por el Protector de los hospitales, el licenciado Tejada "y otros señores". A pesar de no tener censuras explícitas, la representación privada para su control es un procedimiento inusual (solamente puede documentarse, en el caso de Lope, con El blasón de los Chaves de Villalba, como ya se ha indicado); puede que en algún momento, supuestamente anterior a la visión de la pieza por parte de las autoridades, se aconsejara a Lope que revisara la pieza para ajustarla a las necesidades de decoro del momento, quizá también en relación con su estatus de recién cofrade de la congregación de los Esclavos del Santísimo Sacramento. También es importante recordar que la pieza fue escrita para la compañía de Alonso de Riquelme, cuya estrecha amistad con Lope ha sido remarcada recientemente por Alejandro García Reidy [2013: 124]. Según ha estudiado Sònia Boadas en su edición de la comedia [2016: 458-459], es posible que las modificaciones se realizaran a raíz de una petición de Riquelme a Lope y que tuvieran una relación con el conflicto entre la compañía y el convento de las monjas trinitarias que se encontraba en la calle cercana y que se quejaba por la confusión que creaban los ensayos. Según la autora, la necesidad de la revisión: "no debe entenderse como una propuesta coercitiva que limitaba la libertad expresiva del poeta, sino como una recomendación entre socios cuyo objetivo común era crear un producto atractivo y rentable dentro del mercado teatral" [473]. El estudio pormenorizado que hace Boadas del manuscrito autógrafo lleva a demostrar la presencia de intervenciones ajenas a Lope y que van, por un lado, en la dirección de la reescritura impulsada por él, pero por otro lado intentan recuperar los versos tachados correspondientes a la primera versión. Estos elementos parecen remitir, según Boadas, a la voluntad de tener a disposición las dos versiones por parte de la compañía. Lo cierto es que el manuscrito autógrafo presenta unas intervenciones importantes de la mano del mismo Lope, hasta el punto de modificar el título de la obra, que se convierte en La encomienda bien guardada. La versión castigada es la que se imprimió en la Parte $X V$, autorizada por Lope, aunque con el título de La buena guarda que correspondía a la primera versión, quizá por voluntad del mismo dramaturgo. El objetivo de la revisión de Lope tiene que ver con el intento de aligerar o eliminar el constante trasfondo religioso, llevando la obra, 
en la medida de lo posible, hacia un territorio profano: el convento se transforma en un oratorio para doncellas casaderas y la abadesa protagonista, en la reescritura, se convierte en la directora de este oratorio. Cabe señalar que la revisión no parece tener una finalidad estética, sino que se centra en la eliminación de las referencias religiosas. Véase, entre otros, el siguiente ejemplo (vv. 2736-2741):

\begin{tabular}{|l|l|}
\hline \multicolumn{1}{|c|}{ Primera versión } & \multicolumn{1}{c|}{ Segunda versión } \\
\hline Clara, en tu convento estás. & Ya, Clara, en tu casa estás. \\
Entra y en tu celda propia & Entra, que en ese aposento \\
el hábito que dejaste & hallarás cuanto dejaste \\
cuando a tu esposo negaste, & cuando tu honor olvidaste, \\
con tu voto hazaña impropia, & y el de este recogimiento. \\
toma del mismo lugar, & Vuelve a ocupar tu lugar, \\
que en el tuyo quedé yo & que en el tuyo quedé yo \\
cuando Félis te engañó & cuando Félis te engañó \\
\hline
\end{tabular}

La modificación de los papeles lleva al dramaturgo a poner atención explícita hacia la indumentaria, como se aprecia, por ejemplo en la acotación después del v. 372; la primera versión es: "Entre doña Clara, monja, en el hábito que parezca más a propósito" que se modifica en "Entre doña Clara, dama gallarda para casarse, más a propósito vestida en recogimiento", donde la indicación "para casarse" remite al traje, posiblemente un velo que cubría la cara. Al mismo tiempo, Lope aleja el espacio dramático de un contexto español, y sustituye los lugares geográficos concretos (Ciudad Real, Toledo, Sevilla, Castilla, Valencia, Barcelona, el río Tajo, Salamanca, Madrid) con referencias a unos lugares europeos más lejanos (Nápoles, Francia, París, Génova, Italia, Milán, Bolonia). Si bien no puede detectarse una significativa modificación del estilo y del registro, dado que el género sigue siendo el de una comedia hagiográfica, puede en cambio apreciarse como las tipologías de intervención corresponden a los ámbitos indicados por los censores oficiales de otras obras: topónimos, indumentaria, breves sintagmas o palabras concretas. Obviamente, tratándose del mismo autor de la obra, estas modificaciones conllevan a menudo una reescritura completa de la estrofa o de la escena entera que en cambio un censor, o un encargado de la compañía, no habrían realizado por motivos de economía de la revisión y también de competencia artística ${ }^{24}$. La constante vena creativa y la incesante disponibilidad a la reescritura que caracteriza la actividad artística de Lope debió de influenciar también esta fase peculiar del trabajo del dramaturgo profesional: un evento externo que pudo imponer la revisión de la obra bajo determinados criterios, se convierte en una ocasión para reescribir fragmentos largos o hasta secuencias importantes en la estructura, como el principio o el final de la pieza.

En este sentido, reviste especial interés la doble conclusión de la famosa tragedia El castigo sin venganza según está documentado en el manuscrito autógrafo fechado a 1 de agosto de 1631. La distancia con la fecha de la licencia de representación (3 de mayo de 1632), quizá es un primer indicio de algún tipo de retraso impuesto por

24 En cuanto a la modificación del título, remito a las interesantes consideraciones de Boadas [438-443], quien no necesariamente achaca la variante a una intención autocensoria, como en cambio puede suponerse en casos más evidentes como la temprana El rufián dichoso, que se convierte, en la tradición impresa, en El galán dichoso. 
motivos independientes de la voluntad del autor. También ha contribuido a aumentar el interés hacia la historia de la puesta en escena de la pieza una indicación escueta que se encuentra en la impresión suelta que se realizó en 1634 en Barcelona, donde supuestamente el mismo Lope declaró a su dedicatario: "esta tragedia se hizo en la corte sólo un día por causas que a vuestra merced le importan poco" y que "dejó entonces tantos deseosos de verla, que los he querido satisfacer con imprimirla" (79). Esta afirmación ha producido algunas hipótesis de la crítica sobre el contenido político de la pieza o la alusión a personajes de la familia real, especulaciones que luego se han descartado: "Probablemente, las causas que importan poco al lector fueron los conflictos y disputas entre la gente de la farándula, que dieron al traste con la permanencia en cartel de una obra estrenada con éxito" [Pedraza 2015: 179$180)^{25}$. Se ha llegado a suponer la influencia de la polémica literaria con personajes poderosos como el mismo cronista real, José Pellicer; estas tensiones pueden tener que ver con las correcciones de Lope en el autógrafo, pero se trata de suposiciones sin un fundamento documental. En la primera versión, la obra acaba con la muerte del Conde y un breve diálogo en el que el Duque de Ferrara insta a la dama Aurora que decida si casarse con él o con el marqués de Mantua, dejando abiertas ambas soluciones. En un segundo momento, Lope elimina la oferta de matrimonio e introduce la presencia en escena de los cadáveres de los amantes (Casandra y el Conde). Como ha subrayado Valdés [2015: 209], este nuevo final aumenta el patetismo y la conclusión se basa sobre una solución dramatúrgica nueva e importante, aunque produce notables defectos estructurales. Según se confirma por las aprobaciones y licencias de representación que aparecen en la misma página del fragmento añadido, todo hace pensar que fue esta segunda versión la que fue aprobada y puesta en escena. Es difícil aquí hablar expresamente de autocensura, aunque sí puede suponerse la existencia de causas externas que llevaron a la modificación de la importante secuencia final. Podría tratarse de una intervención estilística a partir de una reacción polémica, y Valdés [212] ha llegado a suponer, en el manuscrito, la presencia de la mano del censor amigo de Lope, Tomás Gracián Dantisco, en las modificaciones al mismo texto poético.

Finalmente, cabe recordar que la actividad de publicación de su propio teatro debió de representar para Lope una ocasión para revisar algunos fragmentos y aportar innovaciones a las obras. En algunos casos, el autor pudo aportar censuras para ajustar los textos a la diferente función y difusión prevista para el libro impreso. Aunque solamente pueden hacerse hipótesis sobre la causa de algunas intervenciones sistemáticas, los indicios no faltan.

Por ejemplo, La dama boba (1613) fue publicada en el primer libro de comedias autorizado oficialmente por Lope, la Parte IX (1617) sin tener acceso a su manuscrito original, según sus mismas declaraciones. En la versión impresa se puede apreciar la tendencia a eliminar los pasajes que remiten al dinero como causa del enamoramiento del galán Laurencio: las referencias a la dote extraordinaria que tiene la boba Finea se reducen notablemente y se omite la entera escena de los vv. 185-272, protagonizada por Octavio, padre de Nise y Finea, que se queja de la dificultad de casar a la discreta Nise frente a la rica Finea. También se reduce, en el segundo

25 Más indicaciones en la edición de García Reidy [2013: 46-47]; un resumen pormenorizado de las aportaciones críticas sobre el tema se encuentra en CLEMIT que aprovecha ampliamente el ensayo de Urzáiz, "Más daño hizo Lope". 
acto, el diálogo en el que los galanes se dividen a las dos mujeres de manera poco decorosa con irreverentes comparaciones al juego de las cartas ${ }^{26}$. Todas estas intervenciones parecen vislumbrar un proyecto coherente de atenuación de algunos motivos, aunque no es posible saber con seguridad si se debió directamente a Lope y si este fenómeno debe relacionarse con un evento concreto que impuso un mayor autocontrol del texto.

\section{Conclusiones}

No obstante la imponente labor de recopilación y crítica que se ha realizado sobre el tema de la censura en el teatro de Lope en el Siglo de Oro, la misma tipología de los documentos conservados impide de momento realizar síntesis realmente exhaustivas y satisfactorias. La definición de diferentes etapas de la escritura del dramaturgo, ya establecida con criterios estético-literarios y dramatúrgicos por Oleza, se relaciona con el debate sobre la licitud y se confirma por los eventos de historia del teatro, como los cierres de los corrales, que conllevan una mayor atención de la censura hacia los textos, tendencialmente más abiertos e incontrolados.

En la fase de madurez de la práctica escénica, y también de la trayectoria artística del dramaturgo, aumenta la dificultad de establecer las formas y los temas de interés del censor y escasean los casos explícitos, en un contexto de organicidad del autor dentro de un sistema de producción marcado por la inestabilidad formal del texto literario para las tablas. Sin duda habrá que seguir en el estudio y descripción de las modalidades de reescritura de una obra por parte del dramaturgo o de otros encargados, al mismo tiempo que deberán explicarse las motivaciones de tales intervenciones y su estratificación en los testimonios conservados.

La definición de los límites de la libertad creativa de un autor torrencial pero vinculado a los ritmos del mercado, junto con la atención a la variedad y al "rumor de las diferencias" que acompaña su obra teatral, es un reto que Lope nos exige, porque ayudará a comprender en su complejidad el lugar del dramaturgo en la historia de la cultura y el arte dramático europeo a través de su protagonista más prolífico.

\section{Bibliografia}

Artelope. Base de datos y Argumentos del Teatro de Lope de Vega, dir. Joan Oleza, Universidad de Valencia, 2011-2018, Recurso web $<$ http://artelope.uv.es/>, Fecha de consulta: 9-II-2019.

Badía, Josefa (2014): Los primeros pasos en la comedia nueva. Texos y géneros en la colección teatral del Conde Gondomar, Madrid, Iberoamericana.

Capoia, Stefania (2014): "Variantes, estratos de intervención y textos en el manuscrito autógrafo de La buena guarda y La encomienda bien guardada", Anuario Lope de Vega. Texto, literatura, cultura, XX: 122-158.

Castro, Américo (1922): "Una comedia de Lope de Vega condenada por la Inquisición", Revista de Filología Española, 9-3: 311-314.

26 Con cierta probabilidad, hasta la ausencia en el impreso de pasajes que remiten a la astrología y al poder de las estrellas pueden relacionarse con una tendencia autocensoria. 
CLEMIT: Censuras y licencias en manuscritos e impresos teatrales, dir. Héctor Urzáiz Tortajada, Universidad de Valladolid, 2012, Recurso web <www.clemit.es; y buscador.clemit.es>, Fecha de consulta: 9-II-2019.

Cotarelo y Mori, Emilio (1904): Bibliografia de las controversias sobre la licitud del teatro en España, Madrid, Tip. de la Revista de Archivo, Bibliotecas y Museo, eds. José Luis Suárez, Granada, Universidad de Granada, 1997.

Crivellari, Daniele (2015): "Sobre un manuscrito autógrafo de Lope: Barlaán y Josafat", Revista de Literatura, LXXVII, 153: 75-91.

Ferrer, Teresa (2012): “Lope y la creación de los héroes contemporáneos: La nueva victoria de don Gonzalo de Córdoba y La nueva victoria del Marqués de Santa Cruz", Anuario Lope de Vega. Texto, literatura, cultura, XVIII: 40-62.

Florit Durán, Francisco (2010): "Las censuras previas de representación en el teatro áureo", Cuatro triunfos áureos y otros dramaturgos del Siglo de Oro, ed. Aurelio González, Serafín González y Lilian von der Walde, México D.F., El Colegio de México-Universidad Autónoma Metropolitana-AITENSO: 615-637.

García Berrio, Antonio (1978): Intolerancia de poder y protesta popular en el Siglo de Oro: los debates sobre la licitud del teatro, Málaga, Universidad de Málaga.

García Reidy, Alejandro (2013): La musas rameras. Oficio dramático y conciencia profesional en Lope de Vega, Madrid-Frankfurt am Main, TC/12-Iberoamericana-Vervuert.

Granja, Agustín de la (2006): “Comedias del Siglo de Oro censuradas por la Inquisición (con noticia de un texto mal atribuido a Rojas Zorrilla)", El Siglo de Oro en escena. Homenaje a Marc Vitse, Tolouse, PUM-Consejería de Educación de la Embajada de España en Francia: 435-448.

Iriso Áriz, Silvia (1997): "Estudio de la colección Gálvez: fiabilidad y sentido de los apógrafos de Lope de Vega", Anuario Lope de Vega, III: 99-143.

Márquez, Antonio (1980): Literatura e Inquisición en España 1478/1834, Madrid, Taurus.

Nider, Valentina (2011): “La censura del 'disparate': l'Entremés de la infanta Palancona (Pisa, 1616) e la commedia burlesca Durandarte y Belerma", Leyendas negras e leggende auree, ed. Maria Grazia Profeti y Donatella Pini, Florencia, Alinea: 153-184.

Oleza, Joan (1981): "La propuesta teatral del primer Lope", Cuadernos de filología, III, 1-2: 153-223.

Pellicer, Casiano (1975): Tratado histórico sobre el origen y progreso de la comedia y del histrionismo en España, ed. José María Díez Borque, Barcelona, Labor.

Presotto, Marco (2000): "Reajustes y censuras para la puesta en escena de Los embustes de Celauro", Revista canadiense de estudios hispánicos, XXV (1): 53-66.

- (2000): Le commedie autografe di Lope de Vega. Catalogo e studio, Kassel, Reichenberger. "Libertad y proceso de escritura en Lope de Vega", en Libertad. Libertades. Estudios de Filosofía, Historia y Artes del mundo Ibérico e Iberoamericano, ed. Juan Carlos Garrot Zambrana, Alfredo Gómez Müller, Marie Hélène Soubeyroux, Mónica Zapata, Madrid-Tours, El Barco Ebrio, 2018: 125-147.

Profeti, Maria Grazia (1992): "I bambini di Lope: tra committenza e commozione", en La vil quimera de este monstruo cómico, Kassel, Reichenberber: 173-195.

Sáez Raposo, Francisco (2010): “Cuestiones censorias en la Parte VI de comedias de Lope de Vega: el caso de La batalla del honor", Cuatrocientos años del "Arte nuevo de hacer comedias” de Lope de Vega, ed. Germán Vega García-Luengos y Héctor Urzáiz Tortajada, Valladolid, Olmedo Clásico-Universidad de Valladolid: 937-946.

Urzáiz Tortajada, Héctor (2011): “Arte nuevo de censurar comedias (en tiempos de Lope): La corona merecida", El "Arte nuevo de hacer comedias" y la escena. Actas de las XXXII 
Jornadas de Teatro Clásico de Almagro (julio 2009), ed. Felipe Pedraza y Rafael González Cañal, Ciudad Real, Universidad de Castilla-La Mancha: 99-128.

- (2014): “"Más daño hizo Lope": notas sobre la censura de El castigo sin venganza”, Lecturas críticas sobre el Siglo de Oro: hacia Lope de Vega, coord. Marta Villarino, Graciela Fiadino, Mayra Ortiz Rodríguez, Mar del Plata, Universidad Nacional de Mar: 59-82.

Valdés Gázquez, Ramón (2015): "Sobre el manuscrito y los finales de El castigo sin venganza", El último Lope (1618-1635) y la escena. XXXVI Jornadas de Teatro Clásico de Almagro (julio de 2013), ed. Felipe Pedraza, Rafael González Cañal y Elena Marcello, Ciudad Real, Universidad de Castilla-La Mancha: 179-220.

Vega, Lope de El amigo por fuerza, ed. Gonzalo Pontón y José Enrique Laplana Gil en Comedias de Lope de Vega. Parte IV, coord. Luigi Giuliani y Ramón Valdés Gázquez, Lleida, Milenio-Universitat Autònoma de Barcelona, 2002: 923-1080.

— - La batalla del honor, ed. Ramón Valdés Gázquez en Comedias de Lope de Vega. Parte VI, coord. Victoria Pineda y Gonzalo Pontón, Lleida, Milenio-Universitat Autònoma de Barcelona, 2005: 65-292.

_- La bella malmaridada, ed. Enric Querol Coll en Comedias de Lope de Vega. Parte II, coord. Silvia Iriso, Lleida, Milenio-Universitat Autònoma de Barcelona, 1998: 11751389.

—_, El blasón de los Chaves de Villalba, ed. de José Javier Rodríguez Rodríguez en Comedias de Lope de Vega. Parte X, coord. Ramón Valdés Gázquez y María Morrás, Lleida, Milenio-Universitat Autònoma de Barcelona, 2010: 1187-1361.

—- La buena guarda, ed. de Sònia Boadas en Comedias de Lope de Vega, Parte XV, coord. Luis Sánchez Laílla, Madrid, Gredos, 2016: 427-667.

__, El castigo sin venganza, ed. de Alejandro García Reidy, Barcelona, Crítica, 2009.

- Comedia de Bamba, ed. de David Roas en Comedias de Lope de Vega. Parte I, Lleida, Milenio-Universitat Autònoma de Barcelona, 1997: 559-685.

—- La corona merecida, ed. Fernando Rodríguez-Gallego, en Comedias de Lope de Vega. Parte XIV, coord. J. Enrique López Martínez, Madrid, Gredos, 2015: 583-829.

—_, El cuerdo loco, ed. de José Fernández Montesinos, Madrid, Centro de Estudios Históricos, 1922.

—_, El cuerdo loco, ed. de Antonio Sánchez Jiménez y Adrián Sáez en Comedias de Lope de Vega. Parte XIV, coord. José Enrique López Martínez, Madrid, Gredos, 2015: 727-909.

—, La dama boba. Edición crítica y archivo digital, bajo la dirección de Marco Presotto y con la colaboración de Sònia Boadas, Eugenio Maggi y Aurèlia Pessarrodona. BarcelonaBologna, Prolope-Alma Mater Studiorum - Università di Bologna, CRR-MM, 2015, Recurso web <http://damaboba.unibo.it $>$, Fecha de consulta: 9-II-2019

—- Los embustes de Celauro, ed. Marco Presotto en Comedias de Lope de Vega. Parte IV, coord. Luigi Giuliani y Ramón Valdés Gázquez, Lleida, Milenio-Universitat Autònoma de Barcelona, 2002: 1221-1350.

_- La Francesilla, ed. Marta Latorre Pena en Comedias de Lope de Vega. Parte XIII, coord. Natalia Fernández Rodríguez, Madrid, Gredos, 2014: 569-752.

—- El genovés liberal, ed. Elvezio Canonica, en Comedias de Lope de Vega. Parte IV, coord. Luigi Giuliani y Ramón Valdés Gázquez, Lleida, Milenio-Universitat Autònoma de Barcelona, 2002: 549-668.

_- La imperial de Otón, ed. Emilio Blanco, en Comedias de Lope de Vega. Parte VIII, coord. Rafael Ramos, Lleida, Milenio-Universitat Autònoma de Barcelona, 2009: 11311251.

—_, Laurel de Apolo, ed. Christian Giaffreda, Firenze, Alinea, 2003. 
_- El nacimiento de Ursón y Valentín, reyes de Francia, ed. de Patrizia Campana y José Ramón Mayol Ferrer, en Comedias de Lope de Vega. Parte I, Lleida, Milenio-Universitat Autònoma de Barcelona, 1997: 981-1148.

__ El niño inocente de La Guardia, ed. Fernando Baños Vallejo, en Comedias de Lope de Vega. Parte VIII, coord. Rafael Ramos, Lleida, Milenio-Universitat Autònoma de Barcelona, 2009: 1503-1627.

—_, Las pobrezas de Reinaldos, ed. Teresa Barjau, en Comedias de Lope de Vega. Parte VII, coord. Enrico di Pastena, Lleida, Milenio-Universitat Autònoma de Barcelona, 2008: 327-456.

— Viuda, casada y doncella, ed. Ronna S. Feit y Donald McGrady en Comedias de Lope de Vega. Parte VII, coord. Enrico di Pastena, Lleida, Milenio-Universitat Autònoma de Barcelona, 2008: 1097-1240.

Vitse, Marc (1988): Elements pour une théorie du Théatre espagnol du XVIIe siècle, FranceIbérie Recherche, Toulouse, Université de Toulouse-Le Mirail.

Wilder, Thorton (1952): "New Aids Toward Dating the Early Plays of Lope de Vega", en Varia Variorum, Festgabe für Karl Reinhardt, Münster/Köln, Bölhau: 194-200.

—, (1954): “Lope, Pinedo, some Child-actors, and a Lion”, en Romance Philology, VII: $19-25$.

Zamora Lucas (1941): Florentino, Lope de Vega censor de libros, Larache, Artes Gráficas Boscá. 
